\title{
PENGARUH DIMENSI CUSTOMER VALUE TERHADAP KEPUASAN PELANGGAN TRANSMART BANJARMASIN
}

\author{
Aris Setia Noor,Berta Lestari \\ Fakultas Ekonomi Universitas Islam Kalimantan Muhammad Arsyad Al Banjari \\ Banjarmasin,Indonesia \\ arissetianoor@gmail.com, bertalestaribjm@gmail.com
}

\begin{abstract}
This research was conducted to analyze the effect of customer value dimensions on TransMart customer satisfaction in Banjarmasin. The customer value variables used are value outcomes, process value and enjoyment shopping.

The type of research used is descriptive quantitative. The type of data used is qualitative and quantitative data, while the data sources are primary and secondary data. The population of this study is customers who shop at TransMart Banjarmasin. The sampling technique carried out for this study was determined intentionally. The number of samples taken is 30 customers. The technique of collecting data through observation and questionnaires. Data analysis techniques are carried out using multiple linear regression methods.
\end{abstract}

Keywords: Customer Value and Customer Satisfaction.

\begin{abstract}
Abstrak
Penelitian ini dilakukan untuk menganalisis pengaruh dimensi customer value terhadap kepuasan pelanggan TransMart Banjarmasin. Variabel-variabel customer value yang digunakan adalah outcome value, process value dan shopping enjoyment.

Jenis penelitian yang digunakan adalah deskriptif kuantitatif. Jenis data yang digunakan adalah data kualitatif dan kuantitatif, sedangkan sumber data adalah data primer dan sekunder. Populasi dari penelitian ini adalah pelanggan yang belanja di TransMart Banjarmasin. Teknik sampling yang dilakukan untuk penelitian ini adalah ditentukan dengan sengaja. Jumlah sampel yang diambil berjumlah 30 pelanggan. Teknik pengumpulan data melalui observasi dan kuesioner. Teknik analisis data dilakukan dengan menggunakan metode regresi linier berganda.
\end{abstract}

Kata Kunci : Customer Value dan Kepuasan pelanggan.

\section{PENDAHULUAN}

Pada masa lalu produsen berlomba memproduksi barang yang berkualitas tinggi sebagai keunggulan bersaing tetapi sekarang untuk memiliki keunggulan bersaing yang tinggi produsen harus bisa memuaskan pelanggannya. Salah satu cara untuk mencapai kepuasan pelanggan yaitu dengan cara meningkatkan customer value perusahaan tersebut.
Pelanggan yang telah mencapai kepuasan sangat memungkinkan sekali untuk memberitahukan kepada teman, rekan maupun orang lain akan pengalaman yang mereka dapatkan tentang produk atau jasa perusahaan. Perusahaan dapat meningkatkan pangsa pasarnya melalui pemenuhan kualitas yang akan memberikan keunggulan harga dan customer value. Customer value merupakan nilai yang diberikan oleh pelanggan terhadap 
produk/jasa perusahaan yang ditawarkan kepadanya. Semakin tingginya tingkat persaingan, akan menyebabkan pelanggan menghadapi lebih banyak alternative produk, harga dan kualitas yang bervariasi, sehingga pelanggan akan selalu mencari nilai yang dianggap paling tinggi dari beberapa produk (Kotler 2012).

Organisasi bisnis yang ditinggalkan oleh pelanggan akan menghadapi masalah yang besar karena menurunnya tingkat pendapatan. Namun apabila kepuasan pelanggan terpenuhi maka pelanggan akan terus datang kepada perusahaan untuk memenuhi kebutuhannya, sehingga pelanggan semakin bertambah yang secara tidak langsung keuntungan dan pendapatan akan terus meningkat. maka organisasi bisnis akan tumbuh dan berkembang serta tetap bisa bertahan dalam persaingan.

TransMart Banjarmasin merupakan salah satu tempat berbelanja ataupun hiburan yang ada di Banjarmasin yang mulai beroperasi di tanggal 08 Juni 2018. Kehadirannya menjadi hal baru untuk masyarakat yang ada di Kalimantan Selatan terutama di Banjarmasin, sehingga membuat peneliti ingin menggali lebih dalam lagi pengaruh antara customer value terhadap kepuasan pelanggan.

\section{METODE PENELITIAN}

Teknik analisis yang digunakan dalam penelitian ini adalah regresi linier berganda. Menurut Sudradjat (2004), teknik ini dipilih karena data yang ada berupa interval dan untuk mencari pengaruh antaravariabel $\mathrm{X}$ dan $\mathrm{Y}$, regresi linier berganda merupakan sebuah model regresi yang menggunakan lebih dari dua variabel, dimana fungsinya digambarkan sebagai berikut :

$$
Y=f(X)
$$

Fungsi dari analisis regresi linier berganda yang digunakan dalam penelitian ini digambarkan sebagai berikut :

$$
\begin{aligned}
& Y_{1}=a+b_{1} X_{1}+b_{2} X_{2}+b_{3} X_{3}+e \\
& \text { Di mana : } \\
& \mathrm{Y}_{1}=\text { Kepuasan Pelanggan } \\
& \text { a } \quad=\text { Konstanta } \\
& \mathrm{X}_{1} \quad=\text { Outcome Value } \\
& \mathrm{X}_{2} \quad=\text { Process Value } \\
& \mathrm{X}_{3} \quad=\text { Shopping Enjoyment } \\
& \mathrm{b}_{1}, \mathrm{~b}_{2}, \mathrm{~b}_{3}=\text { Koefisien regresi variabel } \\
& \text { Customer Value } \\
& \mathrm{e} \quad=\text { Faktor gangguan }
\end{aligned}
$$

Pengolahan data dilakukan dengan bantuan software SPSS.

\section{Asumsi Klasik}

Untuk memastikan apakah variabelvariabel penelitian dapat dianalisis dengan menggunakan Regresi Linier Berganda atau tidak, maka diperlukan suatu uji asumsi klasik sebagai persyaratan analisis regresi berganda. Variabel-variabel tersebut harus memenuhi syarat-syarat sebagai berikut:

\section{Uji Multikolinieritas}

Uji multikolinieritas ini digunakan untuk mengetahui ada tidaknya korelasi antara variabel independen. Jika terjadi korelasi, maka dinamakan terdapat problem multikolinieritas. Untuk mengetahui ada tidaknya multikolinieritas antar variabel, dapat dilihat dari Variable Inflation Factor (VIF) dari masing-masing variabel bebas terhadap variabel terikat. Menurut Imam Gozali (2007: 357), jika nilai VIF tidak lebih besar dari 5 maka dalam model tidak terdapat multikolinieritas.

2. Uji Heteroskedastisitas

Uji heteroskedastisitas bertujuan untuk menguji apakah dalam sebuah model regresi terjadi ketidaksamaan varian dari residual dari suatu pengamatan lainnya. 
Jika varian dari pengamatan lainnya tetap, maka disebut homoskedastisitas. Sedangkan apabila variannya berbeda dari satu pengamatan ke pengamatan lainnya disebut dengan gejala heteroskedastisitas. Untuk mengetahui ada atau tidaknya gejala heteroskedastisitas adalah dengan melihat ada tidaknya pola tertentu pada grafik scatter plot. Apabila tidak ada pola yang jelas atau pola tertentu serta titik menyebar di atas dan di bawah angka 0 pada sumbu $\mathrm{Y}$, maka tidak terjadi heteroskedastisitas.

3. Uji Autokorelasi

Autokorelasi ialah adanya korelasi antara variabel itu sendiri, pada pengamatan yang berbeda waktu atau individu. Uji autokorelasi digunakan untuk mengetahui apakah dalam persamaan regresi mengandung korelasi serual atau tidak di antara variabel pengganggu (Imam Gozali 2007: 219), untuk mengetahui adanya autokorelasi digunakan uji Durbin-Watson yang dapat dilihat dari hasil uji regresi dan secara konvensional dapat dikatakan bila angka uji Durbin-Witson mendekati angka 2 (dua) berarti tidak ada autokorelasi.

\section{Uji Normalitas}

Uji Normalitas dilakukan dengan tujuan untuk mengetahui apakah dalam sebuah model regresi baik itu variabel terikat maupun variabel bebas secara terpisah atau secara bersamaan keduanya mempunyai distribusi normal atau tidak. Deteksi normalitas dilakukan dengan melihat penyebaran data (titik) pada sumbu diagonal dari grafik. Dasar pengambilan keputusan yang digunakan:

a. jika data menyebar di sekitar garis diagonal dan mengikuti arah garis diagonal, maka model regresi memenuhi asumsi normalitas.

b. Jika data menyebar jauh dari garis diagonal, maka model regresi tidak memenuhi asumsi normalitas (Imam Gozali, 2007:214).

\section{Pengujian Hipotesis}

Untuk menguji hipotesis yang ada, penulis menggunakan alat uji statistik yaitu:

a. Uji F

Uji ini dilakukan untuk menguji pengaruh variabel terikat secara bersamaan. Tingkat kepercayaan yang digunakan adalah sebesar $95 \%$ atau taraf nyata $(\alpha)$ sebesar $5 \%$. Sedangkan yang menjadi derajat kebebasan adalah $(\mathrm{df})=(\mathrm{k}-1)(\mathrm{n}-\mathrm{k})$. Dalam pengujian ini $\mathrm{F}$ hitung dibandingkan dengan $\mathrm{F}$ tabel, apabila $F$ hitung lebih besar dari $F$ tabel maka hipotesis diterima, yang berarti variabel bebasnya secara simultan mempunyai pengaruh secara nyata terhadap variabel terikat, dan sebaliknya jika $F$ hitung kurang dari $\mathrm{F}$ tabel, maka hipotesis ditolak.

b. Uji t

Uji ini dilakukan untuk menguji pengaruh variabel-variabel bebas terhadap variabel terikat secara parsial. Tingkat kepercayaan yang digunakan adalah sebesar $95 \%$ atau taraf nyata $(\alpha)$ sebesar $5 \%$. Sedangkan yang menjadi derajat kebebasan adalah $:(\mathrm{df})=(\mathrm{n}-\mathrm{k})$ jika $t$ hitung lebih besar dari $t$ tabel maka hipotesis diterima. Sebaliknya jika $t$ hitung kurang dari t tabel maka hipotesis ditolak.

\section{HASIL DAN PEMBAHASAN}

Sebelum data dianalisis, data tersebut telah dilakukan pengujian kenormalan data. Berdasarkan hasil uji normalitas, didapat bahwa data terdistribusi secara normal. Hasil analisis regresi linier terhadap variabel penelitian menunjukkan hasil sebagai berikut pada Tabel berikut: 
maka kepuasan pelanggan Transmart Banjarmasin juga akan turun.

\section{Hasil Pengujian Secara Simultan}

Hasil Analisis Regresi Berganda

\begin{tabular}{|c|c|c|c|c|c|}
\hline $\begin{array}{l}\text { Sim } \\
\text { bol }\end{array}$ & $\begin{array}{c}\text { Variabe } \\
1\end{array}$ & $\begin{array}{l}\text { Koefi } \\
\text { sien } \\
\text { Regre } \\
\text { si }\end{array}$ & $\begin{array}{l}\text { Koefi } \\
\text { sien } \\
\text { Beta }\end{array}$ & $\begin{array}{c}\text { t- } \\
\text { hitu } \\
\text { ng }\end{array}$ & $\begin{array}{c}\text { Prob./ } \\
\text { Sig. }\end{array}$ \\
\hline \multicolumn{2}{|c|}{ Konstanta } & 2,217 & & & \\
\hline $\mathrm{X} 1$ & $\begin{array}{l}\text { Nilai } \\
\text { Hasil }\end{array}$ & 0,299 & 0,296 & $\begin{array}{r}2,52 \\
0\end{array}$ & 0,019 \\
\hline $\mathrm{X} 2$ & $\begin{array}{l}\text { Nilai } \\
\text { Proses }\end{array}$ & 0,093 & 0,099 & $\begin{array}{r}0,88 \\
7 \\
\end{array}$ & 0,384 \\
\hline X3 & $\begin{array}{l}\text { Kenikm } \\
\text { atan } \\
\text { Berbela } \\
\text { nja }\end{array}$ & 0,251 & 0,275 & $\begin{array}{r}2,39 \\
6\end{array}$ & 0,025 \\
\hline \multicolumn{6}{|c|}{$\begin{array}{l}\text { Multiple } R=0,853 \\
\text { R Squared }=0,727 \\
\text { F Ratio }=12,771 \\
\text { Prob }=0,000 \\
n=30\end{array}$} \\
\hline
\end{tabular}

Sumber: Data Primer 2019

Berdasarkan hasil analisis pada Tabel di atas, maka persamaan regresi yang dihasilkan adalah :

$$
\begin{aligned}
& \mathrm{Y}=2,217+0,299 \cdot \mathrm{X}_{1}+0,168 \cdot \mathrm{X}_{2}+ \\
& 0,406 \cdot \mathrm{X}_{3}+\mathrm{e}
\end{aligned}
$$

Koefisien regresi parsial, seluruhnya yang terdiri dari tiga variabel independen (Nilai hasil, Nilai Proses dan Kenikmatan Berbelanja) menunjukkan koefisien regresi yang positif, berarti terdapat pengaruh positif atau searah antara variabel independen (Nilai Hasil, Nilai Proses, dan Kenikmatan Berbelanja) dengan variabel dependen (kepuasan pelanggan). Dengan demikian apabila kualitas pelanggan meningkat maka kepuasan pelanggan Transmart Banjarmasin akan naik. Sebaliknya apabila kualitas pelanggan menurun
Pengujian secara simultan (uji F) digunakan untuk membuktikan hipotesis kedua. Variabel nilai pelanggan (Nilai hasil, Nilai Proses dan Kenikmatan Berbelanja) secara simultan mempengaruhi kepuasan pelanggan Transmart Banjarmasin dengan tingkat kesalahan/signifikansi

$5 \%$. Hasil uji $\mathrm{F}$ dapat dilihat pada tabel 4.15 berikut:

\begin{tabular}{|l|c|c|c|c|c|}
\hline \multicolumn{1}{|c|}{ Model } & $\begin{array}{c}\text { Sum of } \\
\text { Square } \\
\text { s }\end{array}$ & df & $\begin{array}{c}\text { Mean } \\
\text { Squar } \\
\text { e }\end{array}$ & $\begin{array}{c}\text { F } \\
\text { hitun } \\
\text { g }\end{array}$ & Sig. \\
\hline Regression & 108,926 & 5 & $\begin{array}{c}21,78 \\
5\end{array}$ & $\begin{array}{c}12,77 \\
1\end{array}$ & 0,000 \\
\hline Residual & 40,940 & 24 & 1,706 & & \\
\hline Total & 149,867 & 29 & & & \\
\hline
\end{tabular}

\section{Hasil Uji F (Uji Simultan) Anova}

Sumber: Data diolah

Berdasarkan tabel 4.15 di atas

\begin{tabular}{|c|c|c|c|c|}
\hline $\begin{array}{c}\text { Variabe } \\
\mathrm{l}\end{array}$ & $\begin{array}{c}\mathrm{t} \\
\text { hitung }\end{array}$ & Sig.t & $\begin{array}{c}\text { Korelas } \\
\mathrm{i} \\
\text { Parsial }\end{array}$ & $\begin{array}{c}\text { Keteranga } \\
\mathrm{n}\end{array}$ \\
\hline $\begin{array}{l}\text { Nilai } \\
\text { Hasil }\end{array}$ & 2,520 & 0,019 & 0,457 & Signifikan \\
\hline $\begin{array}{l}\text { Nilai } \\
\text { Proses }\end{array}$ & 0,887 & 0,384 & 0,178 & Signifikan \\
\hline $\begin{array}{l}\text { Kenik } \\
\text { matan } \\
\text { Berbel } \\
\text { anja }\end{array}$ & 2,396 & 0,025 & 0,439 & Signifikan \\
\hline
\end{tabular}

dijelaskan bahwa $\mathrm{F}$ hitung lebih besar dari $\mathrm{F}$ tabel ( $\left.\mathrm{F}_{\text {hitung }} 12,771>\mathrm{F}_{\text {tabel }} 2,621\right)$, sehingga $\mathrm{H}_{1}$ diterima dengan tingkat kesalahan $(\alpha)$ sebesar 5\%. Penjelasan tersebut sesuai dengan ketentuan, jika $F$ hitung lebih besar dari $\mathrm{F}$ tabel maka variabel bebas mempunyai pengaruh 
terhadap variabel terikat atau faktor variabel kepuasan konsumen Transmart Banjarmasin dipengaruhi oleh nilai pelanggan (Nilai Hasil, Nilai Proses dan kenikmatan berbelanja). Berdasarkan uraian tersebut dapat disimpulkan, hipotesis yang menyatakan bahwa nilai pelanggan (Nilai Hasil, Nilai Proses dan Kenikmatan Berbelanja) berpengaruh terhadap kepuasan pelanggan Transmart Banjarmasin terbukti diterima.

\section{(1) Hasil Pengujian Secara Parsial} (uji t)

Pengujian secara parsial juga digunakan untuk membuktikan hipotesis pertama, yaitu sebagai berikut:

\section{Tabel 4.16}

Hasil uji t (Uji Parsial)

Sumber : Data diolah

Berdasarkan tabel 4.16 di atas dapat dijelaskan sebagai berikut:

(1.1) Nilai t hitung variabel $\left(\mathrm{X}_{1}\right)$ adalah sebesar 2,520, hasil ini lebih besar dibandingkan dengan t-tabel pada Alpha $5 \% \quad(0,05)$ yaitu sebesar 2,069. Dengan demikian secara parsial variable nilai hasil berpengaruh terhadap kepuasan pelanggan Transmart Banjarmasin dengan tingkat kesalahan variabel sebesar 0,019 (lebih kecil dari 0,05).

(1.2) Nilai t hitung variabel Nilai Proses $\left(\mathrm{X}_{2}\right)$ adalah sebesar 0,887, hasil ini lebih kecil dibandingkan dengan t-tabel pada Alpha 5\% $(0,05)$ yaitu sebesar 2,069. Dengan demikian secara parsial variable Nilai proses tidak mempunyai pengaruh terhadap kepuasan pelanggan Transmart Banjarmasin dengan tingkat kesalahan variabel sebesar 0,384 (lebih kecil dari 0,05).

(1.3) Nilai $t$ hitung variabel Reliability $\left(\mathrm{X}_{3}\right)$ adalah sebesar 2,396, hasil ini lebih besar dibandingkan dengan ttabel pada Alpha 5\% $(0,05)$ yaitu

(1.4) sebesar 2,069. Dengan demikian secara parsial variabel Reliability berpengaruh terhadap kepuasan pelanggan Transmart Banjarmasin dengan probabilitas tingkat kesalahan variabel sebesar 0,025 (lebih kecil dari 0,05).

\section{PENUTUP}

\section{Kesimpulan}

Berdasarkan hasil penelitian yang telah dilakukan, diperoleh beberapa kesimpulan sebagai berikut:

1) Hasil penelitian secara simultan menunjukkan bahwa variable nilai hasil, nilai proses dan kenikmatan berbelanja berpengaruh signifikan terhadap kepuasan pelanggan Transmart Banjarmasin.

2) Hasil penelitian secara parsial menunjukkan bahwa:

(1) Variabel nilai hasil berpengaruh signifikan terhadap kepuasan pelanggan Transmart Banjarmasin.

(2) Variabel nilai proses tidak berpengaruh terhadap kepuasan pelanggan Transmart Banjarmasin.

(3) Variabel kenikmatan berbelanja berpengaruh signifikan terhadap kepuasan pelanggan Transmart Banjarmasin.

\section{Saran}


Berdasarkan hasil kesimpulan tersebut diatas, maka dapat diidentifikasi apa saja yang perlu dilakukan Transmart Banjarmasin agar dapat meningkatkan kepuasan pelanggannya.

1. Transmart Banjarmasin perlu memperhatikan variable nilai pelanggan yang terdiri dari nilai hasil, nilai proses dan kenikmatan berbelanja secara menyeluruh, karena variabel ini mampu meningkatkan kepuasan pelanggan.

2. Transmart Banjarmasin juga perlu memperhatikan variabel nilai pelanggan secara individual seperti; kenikmatan berbelanja dengan menambah fasilitas - fasilitas yang bisa menyenangkan pelanggan.

3. Nilai pelanggan perlu ditingkatkan dengan lebih banyaknya memberikan promosi yang menarik bukan yang sudah - sudah pernah dilakukan, promosi yang tidak sesuai seperti potongan harga tetapi harga tetap mahal tidak lebih murah dari harga distro di jalan - jalan.

\section{Daftar Pustaka}

Anderson, B. F. (2001). The Complete Thinker: A Hand Book of Techniques for Creative and Critical Problem Solving, New Jersey: Englewoo

Desired Value. Industrial Marketing Management, 30, 321-337.

Fandy Tjiptono, dan Gregorius Chandra. 2011. Service, Quality and Satisfaction (ed 3). Yogyakarta. Andi.

Fandy Tjiptono. 2012. Pemasaran Jasa. Edisi kelima. Bayumedia Publishing.
Fransiska Subari. 2010. Jurnal Administrasi Bisnis, Vol.6, No. 2.FISIPUnpar.

Ghozali, Imam, 2007, Aplikasi Analisis Multivariate dengan Program SPSS, Edisi 5, Semarang.qa Riset Bisnis. PT Gramedia Pustaka Utama. Jakarta.

Gujarati, 2007, Dasar-Dasar Ekonometrika, Penerbit Andi, Yogyakarta.

Hurriyati, Ratih (2005), Bauran Pemasaran dan Loyalitas

Konsumen, Bandung Alfabeta

Johannes Supranto. 2007. Pengukuran Tingkat Kepuasan Pelanggan Untuk Menaikkan Pangsa Pasar. PT Rineka Cipta. Jakarta.

Kanaidi, 2010, Pengaruh Customer Value dan Corporate Image Terhadap Loyalitas Pengguna Jasa Paket Pos di Wilayah Pos Bandung Raya. "COMPETITIVE" Majalah Ilmiah, Vol 6 No.2 Desember 2010, ISSN : 0216 : 2539

Kanaidi.2010, Pengaruh Customer Relationship, Citra Perusahaan, dan Customer Trust Terhadap Loyalitas. "COMPETITIVE" Majalah Ilmiah, Volume 6 No.2. Desember 2010, ISSN : 0216 $-2539$

Kotler, dan Keller. (2012). Manajemen Pemasaran. Edisi 12. Jakarta: Erlangga 
Kotler, Philip, 2012. Manajemen

Pemasaran (Terjemahan).

Edisi Milenium. Jilid 1. PT

Prenhallindo. Jakarta.

Saifuddin Azwar. 2003. Reliabilitas

dan Validitas. Pustaka

Pelajar. Yogyakarta.

Sucherly. 2004. Metodologi Penelitian Ekonomi. Program Pasca Sarjana Universitas Padjadjaran Bandung.

Sudradjat. 2004. Statistika Sosial.

Program Pascasarjana

Universitas Padjadjaran

Bandung.
Woodruff, R B (2007), 'Customer value: the next source for competitive advantage', Journal of the Academy of Marketing Science, 25(2), 139-153

Zeithaml, Valeri. A (2007) "Customer Perception of Price, Quality and Value: A Means Models and Synthesis of Evidence" Journal of Marketing, Vol 52. No 3 